\title{
Towards a Comprehensive Understanding of Bipolar Disorder: In Vivo MRS Investigation of the Phosphatidylinositol Cycle
}

\author{
Brent M. McGrath*, BSc, MSc
}

\begin{abstract}
At present, both the neuropathophysiology of bipolar disorder as well as the mechanism(s) through which current mood-stabilizing agents provide symptom relief are unknown. Through the recent utilization of magnetic resonance spectroscopy (MRS), progress has been made; with optimistic interest being focused on the phosphatidylinositol (PI) cycle as a likely neuropathophysiological factor in bipolar disorder. The present manuscript reviews this interesting and promising area, placing emphasis on the magnetic resonance spectroscopy investigations of PIcycle function in bipolar disorder reported to date. While relatively few well-designed MRS studies have investigated PI-cycle function in bipolar disorder, current evidence does lend support to PI-cycle involvement in bipolar neuropathophysiology as a means through which mood-stabilizing agents act; pointing to PI-cycle dysfunction as an important neuropathophysiological factor in bipolar disorder. However, there still remains a dearth of information about this interesting hypothesis. In addition to lithium, more data is needed regarding the effects on PI-cycle function of the other commonly prescribed mood-stabilizing agents. As well, studies investigating the temporal relationship between medication effect on PI-cycle functioning and symptom improvement are warranted. In tandem with clinical MRS investigation of bipolar disorder, further preclinical study of the neurochemical effects of mood-stabilizing agents is needed. Finally, greater methodological rigor needs to be implemented during the design phase of any future MRS investigation into bipolar disorder, with particular attention aimed at recruiting a large homogenous sample of bipolar patients.
\end{abstract}

KEY WORDS: Bipolar disorder, magnetic resonance spectroscopy, inositol, mood stabilizer, lithium, valproate, carbamazepine, lamotrigine and olanzapine

\section{BACKGROUND}

"The subject of the following ... will be the Science of Psychiatry. It is true that, in the strictest terms, we cannot speak of the mind as becoming diseased, whether we regard it as a separate entity or as the sum total of our subjective experience. And, indeed, from the medical

*To whom correspondence should be addressed: Brent M. McGrath, Department of Psychiatry, Mackenzie Centre, University of Alberta, 8440-112 Street, Edmonton, Alberta, Canada, T6G 2B7, Phone: 780-492-6028, Fax: 780-407-6672

email: brent.mcgrath@ualberta.ca point of view, it is disturbances in the physical foundations [emphasis his] of mental life which should occupy most of our attention."

$$
\text { Dr. Emil Kraepelin (1) }
$$

Although originally posited almost one hundred years ago, Kraepelin's (1) emphasis on the physical manifestations of psychiatric illness is still very much at the foundation of our understanding of mental illness today. During his time, investigational methodology for the study of the neuropathophysiological explanations surrounding psychiatric illness were only in their mere 
infancy; something Kraepelin (2) himself was keenly aware of. Even today, psychiatric practice and research very much depend upon the physical and behaviour manifestations of psychiatric illness. Indeed, it is through patients' physical sensations, perceptions and behavioural manifestations that we come to diagnosis the malady of the mind. Moreover, in the clinical milieu it is the changes - by way of improving or worsening - in these experiences that are often used as the indicator of treatment success (or failure). These deviations from what constitute the normal behavioural range are no more expressive than among individuals suffering from bipolar disorder (or manic-depressive illness).

The purpose of the present manuscript is to review and discuss the current state-of-the-science concerning nuclear magnetic resonance spectroscopy (MRS) research in bipolar disorder, with particular emphasis placed on investigations that have focused on phosphatidylinositol (PI)-cycle activity in patients and healthy volunteers. The review will begin with a brief overview of the symptoms of bipolar disorder and their treatment, as well as a brief introduction to MRS methodology and a discussion of the relevance of PIcycle activity to bipolar neuropathophysiology. Finally, the findings to-date in the area of PI-cycle MRS research in bipolar disorder will be reviewed and synthesized, limitations will be highlighted, and improvements and directions for future research will be outlined.

\section{Bipolar Disorder}

Originally described by Soranus (3), and defined by Aretaeus (4), the shift between depressive stupor, euthymic serenity and manic excitement generally characterize the existence of the bipolar patient. These states, in turn, consist of disturbances in mood, cognition, perception and behaviour (5). Medical consultation or first hospitalization for bipolar disorder generally occurs between the ages of 25 and 30 (6), usually as a result of manic symptoms (7). However, sub-acute symptom onset is believed to occur many years preceding this (8), with depressive symptoms most frequently reported at first episode. The course of bipolar disorder is usually a chronic, cycling one. Classically, the lifetime prevalence of bipolar disorder was estimated to be about $1 \%$, equal among men and women (9); however, current evidence lends more to an estimate of about $5 \%$ (10). The discrepancy can, in part, be attributed to a shift in the conceptualization of the disorder, from a unipolar-bipolar dichotomy to that of a
Table 1. Proposed Bipolar Diagnostic Spectrum*

\begin{tabular}{|c|c|}
\hline Presentation & Description \\
\hline Bipolar $1 / 2$ & Schizobipolar disorder \\
\hline Bipolar I & Manic-depressive illness \\
\hline Bipolar $I^{1} / 2$ & Depression with protracted hypomania \\
\hline Bipolar II & $\begin{array}{l}\text { Depression with spontaneous discrete } \\
\text { hypomanic episodes }\end{array}$ \\
\hline Bipolar $\mathrm{II}^{1} / 2$ & Depression superimposed on cyclothymia \\
\hline Bipolar III & $\begin{array}{l}\text { Depression plus hypomania occurring in } \\
\text { association with antidepressant or other } \\
\text { somatic treatment }\end{array}$ \\
\hline Bipolar III $1 / 2$ & $\begin{array}{l}\text { Prominent mood swings in association with } \\
\text { substance and/or alcohol (ab)use }\end{array}$ \\
\hline Bipolar IV & Depression superimposed on hyperthymia \\
\hline
\end{tabular}

*(11, 14, reproduced with permission)

bipolar spectrum (11) (Table 1). Put in context, in its Global Burden of Disease study, the World Health Organization noted that major depression and bipolar disorder are, respectively, the first and sixth ranked causes of years lived with disability among people in developed nations $(12,13)$. This helps to underscore the need for early and precise diagnosis as well as more effective treatments for individuals suffering from a bipolar spectrum disorder.

\section{Pharmacological Treatment}

With regard to treatment of bipolar disorder, the expansion in the array of available pharmacological treatments has provided effective treatment options for clinicians and symptomatic relief for patients. Akin to this development has been a change in the definition of what constitutes a mood-stabilizing agent. Early attempts at defining the ideal mood-stabilizing agent focused on the agent's ability to treat at least one principle symptom (mania or depression) of the illness without worsening any other aspect, while still being safe and well tolerated (14). While not entirely abandoned, Kasper (16) makes the point that successful symptom treatment and prevention in bipolar disorder is not easily attainable with the use of only one medication; indicating a need for a "multi-pronged" approach. According to Keck and colleagues (17), this can be explained in terms of a change in the definition of the properties that characterize mood-stabilizing medication as a result of variation in both the properties

\footnotetext{
' Lithium was originally discovered by Johann August Arfvedson in 1817, followed in 1880 by its introduction into the field of psychiatry, by John Aulde and Carl Lange, for the prophylactic treatment of depression. Shortly after 1880, cases of lethal lithium toxicity resulted in widespread discontinuation of lithium in medicine; only to be re-introduced following publication of the findings of John Cade in 1949.
} 
a.

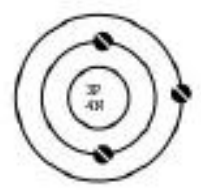

b.

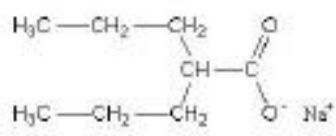

c.

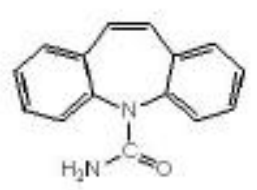

d.

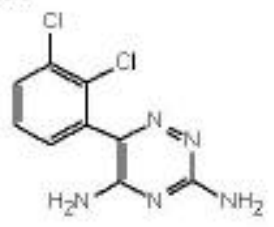

e.

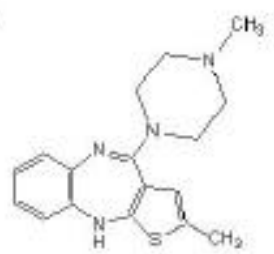

Figure 1. Structural Dissimiliarities of Commonly Prescribed Mood-Stabilizing Agents: a. lithium, b. valproate, c. carbamazepine,

d. lamotrigine, e. olanzapine.

of specific medications and the clinical characteristics of the illness.

To date, the mainstay of treatment for patients with bipolar disorder is the monovalent cation, lithium (18). Lithium's utility and efficacy as a psychoactive agent particularly in the treatment of the manic symptoms of bipolar disorder - was serendipitously re-discovered ${ }^{1}$ by John Cade, an Australian psychopharmacologist, in 1949 (19). Now, it is well established that lithium is effective in both the acute treatment of mania and the long-term prophylaxis of manic and depressive episodes (20). However, findings to date have reported that lithium is only effective in between $50 \%$ and $70 \%$ of bipolar patients $(21,22)$. To improve on this, other agents with mood-stabilizing properties have been introduced. Among these, the anticonvulsants valproate, a propylpentanoate, and carbamazepine, a carboxamide, are currently the most commonly prescribed. Together, all three agents share a common profile in the treatment of bipolar disorder. Namely, all three agents are reportedly more effective in treating acute mania than acute depression (23), and all have reported utility in long-term prophylaxis (20).

Recently, the phenyltriazine anticonvulsant, lamotrigine, was found to have efficacy in the treatment of bipolar I disorder, particularly in the depressive phase of the illness $(24,25)$. This is particularly important given that it is the depressive symptoms that are most responsible for morbidity and mortality in patients with bipolar disorder (26). However, there is no demonstrated efficacy for lamotrigine in the treatment of acute manic symptoms (27).

Conventionally known for their calming and sedating effects, the use of typical antipsychotics in the treatment of bipolar disorder have met with limited success. According to Tohen and Tollefson (28), the side-effect profile, and high risk of inducing depressive symptoms and of increasing cyclicity made the typical antipsychotics a less than ideal treatment choice for bipolar disorder. However, the introduction of the atypical antipsychotics sparked a renewed interest in the use of antipsychotics in patients with bipolar disorder, particularly in those patients who are non-responsive to traditional mood-stabilizing agents. Moreover, the improved profile of the atypical antipsychotics has provided a new avenue of treatment options for bipolar disorder. Among these agents, the thienobenzodiazepine, olanzapine, has offered the most promise; however, more research is needed to determine the range of symptom coverage for these new generation antipsychotics, both alone and in combination with other mood-stabilizing agents.

Thus, as noted by Keck and associates (17), the most important goals of pharmacological treatment and management of bipolar disorder are the "prevention of mood episodes, eradication of interepisode subsyndromal symptoms and inhibition of the inherent cyclicity and mood lability". Key to this success is a unified understanding of both the neuropathophysiology of the condition as well as the mechanism(s) through which currently known effective medications offer relief. With this in mind, all the agents outlined above have some degree of moodstabilizing properties, all belong to different chemical classes and have distinctly different structures (Fig. 1).

This has made it difficult to establish a unifying hypothesis regarding the means through which different medications act, and, by extension, the neuropathophysiology of bipolar disorder. With the introduction, and insightful application of new investigational technologies the ability to study medication effects and the neuropathophysiology of psychiatric disorders, including bipolar disorder, has been greatly enhanced.

\section{Nuclear Magnetic Resonance}

Recent advances in brain-imaging methods, specifically in nuclear magnetic resonance (NMR) have made it possible to study bipolar disorder in vivo. NMR can provide structural (anatomic and volumetric), functional (regional brain activation) and biochemical (metabolic) information. Of particular interest, MR spectroscopy (MRS) allows for the in vivo study of neurochemical and metabolic processes in bipolar patients, both pre- and post-treatment (29). This has provided direction for new avenues of research as well as new information about neurotransmitter and second messenger signaling pathways; helping bridge the gap 
between the laboratory and the clinic (30). In bipolar disorder, particular interest has focused on the PI-cycle, specifically on the role of myo-inositol in the neuropathophysiology of the illness.

\section{INOSITOL-DEPLETION HYPOTHESIS}

At present, both the neuropathophysiology of bipolar disorder as well as the mechanism(s) through which current mood-stabilizing agents provide symptom relief are unknown. A promising avenue for research was uncovered when Allison and associates (31,32) discovered that, in rat brain, lithium administration attenuates the breakdown of the inositol monophosphates into myo-inositol, resulting in an increase in the concentration of the inositol monophosphates and a corresponding decrease in the concentration of myo-inositol (Fig. 2). Attenuating production of myo-inositol slows inositol-1,4,5trisphosphase $\left(\mathrm{IP}_{3}\right)$-dependent intracellular calcium release (33), which in turn down-regulates the release of several neurotransmitters from synaptic vesicles.

In neurons, the PI-cycle is activated through guanine nucleotide-binding $\left(\mathrm{G}_{\mathrm{q}}\right)$ protein coupled ligand binding of a number of receptor/ receptor subtypes, including; adrenergic $\left(\alpha_{1 \mathrm{~A}}\right.$ and $\left.\alpha_{1 \mathrm{~B}}\right)$, glutaminergic $\left(\mathrm{mGlu}_{1}\right.$ and $\left.\mathrm{mGlu}_{2}\right)$, serotonergic $\left(5-\mathrm{HT}_{1 \mathrm{C}}\right.$ and 5-HT $\mathrm{HT}_{2}$, dopaminergic $\left(\mathrm{D}_{1}\right)$ and cholinergic $\left(\mathrm{M}_{1}\right.$ and $\left.\mathrm{M}_{3}\right)$ (34) among others. Given the intricacies and interactions of these various receptors, dysfunction in PI-cycle activity may disrupt signaling between important neural networks, making the PI-cycle an important investigational target and possibly an important therapeutic target as well.

Building on the findings of Allison and associates $(31,32)$, Berridge and colleagues (35) hypothesized that the clinical utility of lithium in bipolar disorder may be due to myo-inositol depletion. Moreover, they noted that lithium's inhibition of the enzyme involved in the breakdown of inositol monophosphates $\left(\mathrm{IP}_{1}\right)$ to myoinositol, the enzyme being inositol monophosphatase
(IMPase), is uncompetitive (binding to the enzymesubstrate complex), and that this inhibition occurs at therapeutically relevant plasma concentrations (0.5-1.0 $\mathrm{mEq} / \mathrm{L})(35)$. Thus, lithium would be expected to only attenuate phosphatidylinositol turnover in overstimulated cells, through binding with the IMPase-IP 1 complex (36); in effect reducing the usual neuronal responses (i.e. calcium release and related downstream effects) to receptor activation. Interestingly, lithium's actions on the PI-cycle appear to be specific to brain rather than peripheral PI-linked signaling systems, possibly due to the brains limited access to free inositol as a result of the blood-brain barrier (36) and/or because only particular neuronal populations are vulnerable to lithium (37). Any decrease in myo-inositol concentrations should also decrease the turnover of $\mathrm{PIP}_{2}$ into $\mathrm{IP}_{3}$. Such a down-regulation of agoniststimulated $\mathrm{IP}_{3}$ production $(38,39)$, as well as all inositol-derived membrane phospholipids (PI, PIP, $\mathrm{PIP}_{2}$ ) (40), has been reported in rat brain following lithium treatment. Moreover, Williams and colleagues (41) recently reported that lithium, sodium valproate and carbamazepine all inhibit the collapse of sensory neuron growth cones and increase growth cone area, but that inositol administration reverses these effects, thus implicating inositol-depletion in the action of three commonly used mood-stabilizing agents. From these findings, it is purported that medications effective in mood-stabilization may act via inositol-depletion. The so-called inositol-depletion hypothesis remains perhaps the most widely accepted hypothesis for lithium's mechanism of action in bipolar disorder (42). By inference, this may point to hyperactivity of the PIcycle - namely increased myo-inositol and inositol derivatives - in brain as a physiological factor involved in the symptom manifestation (mania and depression) of bipolar disorder.

\section{MAGNETIC RESONANCE SPECTROSCOPY}

The physical-chemical properties of human tissue

Table 2. ${ }^{1} \mathrm{H}$ and ${ }^{3} \mathrm{P}$ MRS detectable metabolites considered relevant to bipolar disorder.

\begin{tabular}{lll}
\hline Nuclei & Metabolite (abbreviation) & Physiological Interpretation \\
\hline${ }^{\prime} \mathrm{H}$ & N-acetylaspartate (NAA) & Marker of neuronal viability \\
& Glutamate (Glu) \& Glutamine (Gln) & Glutamine - astrocyte marker \\
& or generally (Glx) & Glutamate - neurotoxin \\
& Creatine+Phosphocreatine (Cr) & Cellular metabolic marker \\
& Choline (Cho) & Marker of phospholipid metabolism and membrane turnover \\
& Myo-inositol (mI) & Glial marker and cell volume regulator \\
\hline${ }^{31} \mathrm{P}$ & Phosphomonoesters (PME) & Phospholipid anabolic marker \\
& Phosphodiesters (PDE) & Phospholipid catabolic marker \\
& Phosphocreatine (PCr) & Cellular metabolic marker \\
& Adenosine Triphosphates $(\alpha-, \beta-, \gamma-\mathrm{ATP})$ & Cellular metabolic marker \\
& Inorganic Phosphate (Pi) & Cellular metabolic marker \\
\hline
\end{tabular}




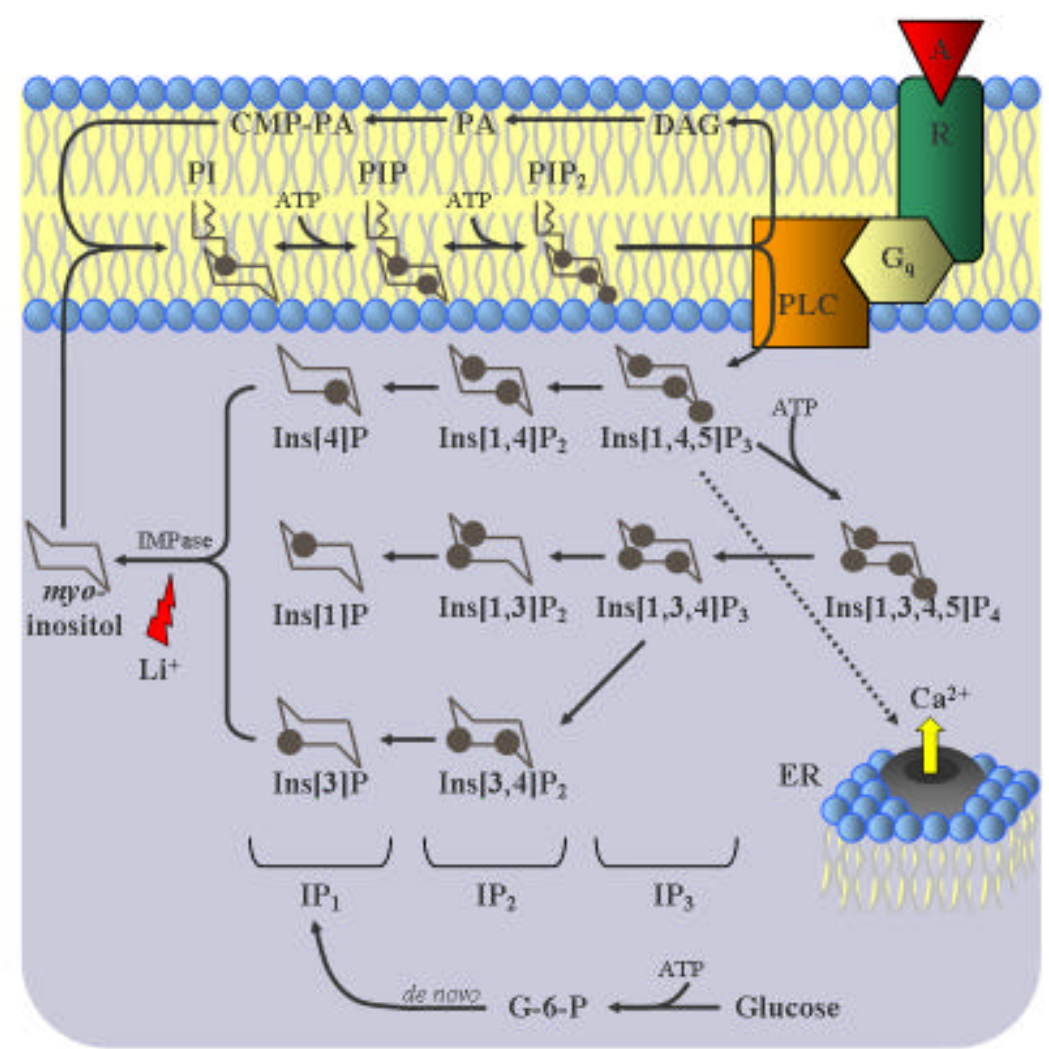

Figure 2. The Phosphatidylinositol (PI) second messenger system works as follows. An agonist (A) binds to a receptor complex, made up of a receptor (R), $\mathrm{G}_{\mathrm{q}}$-protein, and phospholipase $\mathrm{C}$ (PLC). Agonist binding leads to the PLC-catalyzed breakdown of phosphatidylinositol 4,5bisphosphate $\left(\mathrm{PIP}_{2}\right)$ into inositol-1,4,5-trisphosphase $\left(\operatorname{Ins}[1,4,5] \mathrm{P}_{3}\right)$ and 1,2-diacylglycerol (DAG). Ins[1,4,5] $\mathrm{P}_{3}$ subsequently binds to specific receptors on the endoplasmic reticulum (ER) causing the release of stored intracellular calcium $\left(\mathrm{Ca}^{2+}\right) . \quad \mathrm{IP}_{3}$ is sequentially broken down into inositol bisphosphates $\left(\mathrm{IP}_{2}\right)$, inositol monophosphates (IP1) and finally, into myo-inositol. Myo-inositol can also be synthesized de novo from glucose-6-phosphate (G-6-P), through an $\mathrm{IP}_{1}$ intermediate. The metabolism from $\mathrm{IP}_{1}$ to myo-inositol is catalyzed by the enzyme inositol monophosphatase (IMPase), which is uncompetively inhibited by lithium $\left(\mathrm{Li}^{+}\right)$. Reduced levels of myo-inositol prevent the efficient resynthesis of PI from myo-inositol and cytidine monophosphorylphosphatidate (CMP-PA). The large dark circles indicate the location of each phosphate molecule within each respective metabolic intermediate.

facilitate the use of NMR techniques for the safe in vivo investigation of human physiology. More specifically, these properties include the presence of compounds or molecules that contain magnetically active nuclei (43); with hydrogen-1 $\left({ }^{1} \mathrm{H}\right)$ and phosphorous-31 $\left({ }^{3} \mathrm{P}\right)$ being two of the most common nuclei species investigated. While magnetic resonance imaging (MRI) provides anatomical data, utilizing the same basic principles MRS goes beyond this, providing biochemical and metabolic data from brain regions of interest (or volumes of interest) in the study of psychiatric disorders (44). With currently available magnetic field strengths (1.5 Tesla (T) to $4.7 \mathrm{~T}$ ) several biogenic compounds and amino acid neurotransmitters are MRS detectable (Table 2). When placed in this strong magnetic field and penetrated by a radio frequency (rf) pulse, relative quantification of these metabolites can be determined (in relation to a reference compound) and depicted as chemical shift spectra (in parts per million, ppm), with the area under the curve representing the relative concentrations of the metabolites of interest (Fig. 3).
As a general rule, as magnetic field strength increases, so too does the resolution between metabolite resonant frequencies and the single-to-noise ratio (46). In this regard, it is important to note that with commonly utilized field strengths $(1.5 \mathrm{~T}$ to $3 \mathrm{~T})$, the phosphomonoester (PME) peak observed in the ${ }^{31} \mathrm{P}$ MRS spectra (Fig. 3B) contains contributions from several sugar phosphates, including phosphoethanolamine, phosphocholine and the inositol monophosphates. However, changes in the PME peak observed in bipolar disorder, both pre- and posttreatment, are postulated to be the result of changes in the concentration of the inositol monophosphates (47). This assumption has been substantiated from preclinical findings with high-field MRS (9 $\mathrm{T}$ to $18.8 \mathrm{~T}$ ). At these higher field strengths, the inositol monophosphate peak does not contain contributions from other neurometabolites, and changes in inositol monophosphate concentrations have been reported following treatment with lithium and sodium valproate in rat brain (48). As clinical magnets with higher 

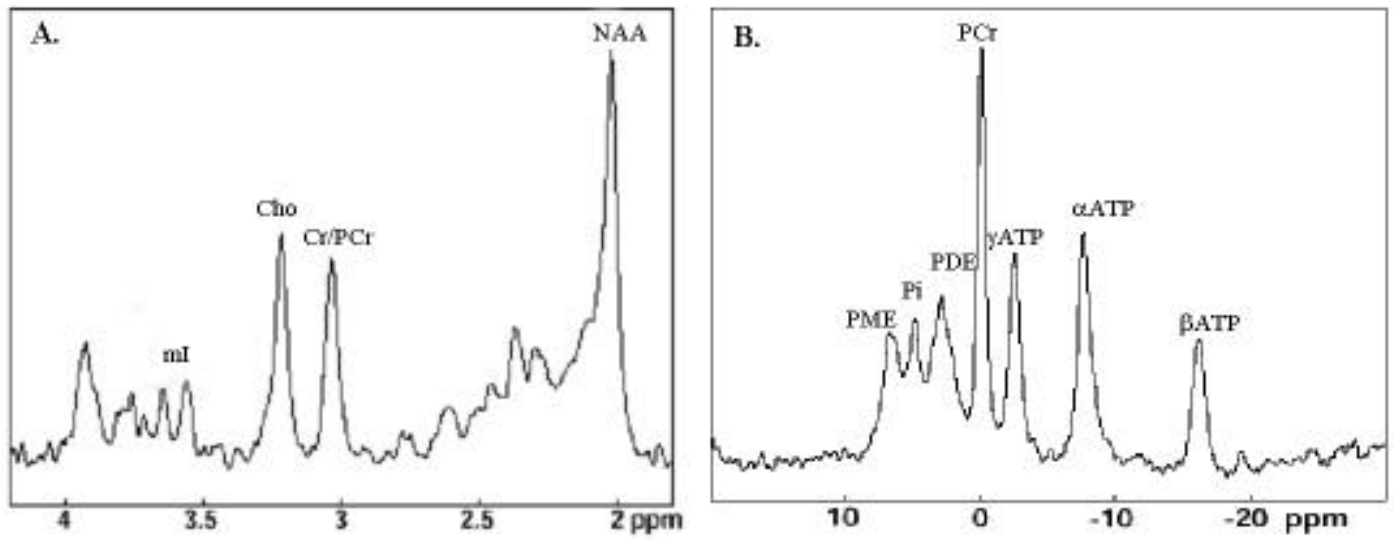

Figure 3. A. ${ }^{1} \mathrm{H}$, and B. ${ }^{31} \mathrm{P}$ MRS Spectra of the Temporal Lobe at 3 Tesla (45, reproduced with permission)

magnetic field strengths $(>3 \mathrm{~T})$ become more widely used, it will be possible to separate out the PME constitutes, including the inositol monophosphates, into individual peaks.

\section{CURRENT FINDINGS}

Principal to the investigation of PI-cycle hyperactive as a causative factor in the neuropathophysiology of bipolar disorder is validation of the inositol-depletion hypothesis as the underlying means through which mood-stabilizing agents act. Towards this end, research has begun to focus more on in vivo MRS investigations of bipolar illness and treatment. However, given the remarkable potential of this approach, relatively few studies have been aimed specifically at investigating inositol depletion; most of which have been done by only a handful of investigators focusing primarily on the effects of lithium. To follow is a synthesis of the findings reported to date, parceled according to bipolar symptomatology (i.e. depressed, manic and euthymic). In the final paragraph, findings from patient studies are contrasted and evaluated with those from studies of healthy volunteers.

\section{Bipolar Depressed}

In a study of unmedicated depressed bipolar and unipolar patients, Frey and associates (49) reported reduced myo-inositol concentrations in the frontal lobes of patients compared to healthy controls, although this finding was significant only when the groups were paired by age.

In a well-conducted study by Moore and colleagues (50) in which absolute metabolite concentrations were measured, a reduction of myo-inositol concentrations were reported in the frontal lobe of medicated depressed bipolar patients, but not in the occipital, parietal or temporal regions, following both acute (5-7 days) and chronic (3-4 weeks) lithium treatment. In a separate study, no difference in myo-inositol concentrations were reported for the anterior cingulated cortex between depressed bipolar patients and healthy controls (51). Kato and associates (52) also reported higher PME concentrations in the frontal lobe of lithium-treated depressed bipolar patients when compared to those in the euthymic state. In two separate studies, Kato and associates $(53,54)$ found higher PME concentrations in the frontal lobe of lithium-treated depressed bipolar patients, compared to both euthymic patients and healthy controls. It is unclear if these PME findings are specific to depressed bipolar patients, as similar findings have been reported in some studies of unipolar depressed patients (55), but not all $(52,56)$. Furthermore, it is also unclear whether myo-inositol concentrations are normal in unipolar depressed patients $(57)$ or if they are decreased $(58,49)$.

\section{Bipolar Manic/Hypomanic}

In a study examining patients before and after lithium treatment, there was a trend at baseline towards higher myo-inositol concentrations in the anterior cingulated cortex of manic bipolar children compared to healthy controls (59). Following 7 days of lithium treatment, myo-inositol concentrations in the anterior cingulated cortex were significantly reduced in the manic children compared to the healthy controls. In a follow-up study the same group reported increased myo-inositol concentrations in the anterior cingulated cortex of manic bipolar children compared to healthy controls, thus confirming the trend observed in their early study (60). They found no difference between the two groups for myo-inositol concentrations in the occipital cortex.

Reduced myo-inositol was observed in the basal ganglia of 4 lithium-treated manic bipolar patients, while no difference was observed for occipital cortex when compared to healthy controls (61). In three studies one group found higher PME concentrations in the frontal lobe of lithium-treated manic and hypomanic bipolar patients compared to euthymic bipolar patients 
and healthy controls $(62,63,53)$. However, this finding was not supported in a subsequent study carried out by the same group (54). A study of manic and mixed bipolar patients, most of who were receiving sodium valproate in addition to other medications (except 3 patients who were receiving sodium valproate monotherapy), found no differences in frontal lobe myoinositol concentrations when compared to healthy controls (64).

\section{Bipolar Euthymic}

Using ${ }^{1} \mathrm{H}-\mathrm{MRS}$, no differences in frontal lobe myoinositol concentrations were observed between unmedicated euthymic bipolar patients $(\mathrm{n}=20)$ and healthy controls (65). Two ${ }^{31} \mathrm{P}-\mathrm{MRS}$ studies reported significantly lower PME concentrations in the frontal (66) and temporal (67) lobes of unmedicated, euthymic bipolar patients compared to healthy controls. In contrast, however, another study found no difference in PME concentrations in the frontal lobe of unmedicated euthymic bipolar patients when compared with healthy controls (68). It should be noted that in the latter study the size of the patient group was relatively small $(n=7)$, and patients had discontinued lithium during a wide time period before the ${ }^{31} \mathrm{P}-\mathrm{MRS}$ examination (from 11 365 days).

Among medicated euthymic bipolar patients, a small ${ }^{1} \mathrm{H}-\mathrm{MRS}$ study reported no changes in temporal and parietal lobe myo-inositol concentrations following lithium treatment in bipolar patients $(n=8)$ (69). Several studies utilizing ${ }^{31} \mathrm{P}$ MRS suggest that euthymic bipolar patients treated with lithium have PME concentrations that are either reduced $(63,70)$ or not significantly different $(53,54,71,72)$ from healthy controls. In the studies by Murashita and colleagues (71) and Hamakawa and associates (72) not all patients were receiving lithium. Consistent with these findings, Silverstone and colleagues (45) reported no difference in frontal lobe PME concentrations between lithiumtreated euthymic bipolar patients and healthy controls. Moreover, in the same study they also reported that euthymic bipolar patients treated chronically with sodium valproate had similar myo-inositol and PME levels when compared to healthy controls as well as lithium-treated euthymic bipolar patients (45). In the one study done in children, no differences in frontal lobe myo-inositol concentrations were found between the 15 euthymic bipolar children, many of whom had been on sodium valproate, and the healthy controls (73).

\section{Healthy Volunteers}

In two studies in healthy volunteers administered lithium for 1 week, Silverstone and colleagues $(74,75)$ did not observe any significant effect of lithium on frontal lobe myo-inositol concentrations. In addition, they found no change in frontal lobe PME concentrations pre- and post-lithium, although an increase has been reported by another group (76).

In the same study, Silverstone and colleagues (75) found that in lithium-treated healthy volunteers given dextro-amphetamine (a putative human model for mania (77)), frontal lobe PME concentrations increased. This finding may be consistent with the findings (discussed previously) of increased frontal lobe PME concentrations in manic $(62,63)$ and hypomanic (53) bipolar patients.

\section{LIMITATIONS}

The newness of the technology combined with the debilitating course of the illness, urgency of treatment and the stringent requirements of any well-designed investigation have lead to several common, but significant limitations in the MRS studies done to date. These limitations can be segregated into two broad types: those relating to the technical aspects of MRS, and those relating to the clinical aspects of psychiatric research.

\section{Technical}

From a purely technical standpoint, two areas warrant scrutiny. First, the vast majority of the studies have relied on the measurement of metabolite change as a ratio between the metabolite of interest (numerator) and some internal standard (denominator). From the ${ }^{1} \mathrm{H}$ findings above it is evident that most have used the creatine+phosphocreatine peak as the internal standard. In phosphorous MRS, phosphocreatine is also one of the main internal standards of choice for many of the published investigations. Irrespective of the metabolite used, the same criticism applies. This approach to quantification relies on the assumption that the standard comparator peak is unchanging, an assumption whose validity has recently been called into question. As a case in point, Hamakawa and associates (78) found that creatine concentrations are significantly reduced in the frontal lobe of bipolar depressed, when compared to euthymic patients. Similiarly, Kato and colleagues (54) have reported significantly lower concentrations of phosphocreatine in the frontal lobe of lithium-treated bipolar II patients; negatively correlating this decrease with scores on the Hamilton Rating Scale for Depression. These changes in phosphocreatine levels were not found in bipolar I patients (60), possibly indicating a difference in energy metabolism between bipolar I and II. Finally, Deicken and colleagues (79) have reported higher creatine concentrations in the anterior and mediodorsal thalamic regions in euthymic bipolar patients. Moreover, other factors related to 
illness, treatment, age and gender might affect the reliability of this approach. As a result, the use of brain water concentration, or an external standard of known concentration as the reference peak is warranted in future studies utilizing MRS as an investigational tool.

The second technical limitation has been the use of low field strength magnets, with most studies utilizing $1.5 \mathrm{~T}$ and $2 \mathrm{~T}$ magnets. Of concern is the low chemical shift dispersive power, often resulting in peak overlap between individual metabolites of interest, as in the case of myo-inositol and glycine, and the Glx peak, which contains contributions from glutamate, glutamine and GABA. Newly available magnets with higher field strengths, including 3T, 4.7T and even 8T, as well as the optimization of pulse sequences specifically targeting individual metabolites of interest will provide better spatiotemporal resolution and higher sensitivity; which is key to any future advances in spectroscopic investigation of bipolar disorder.

\section{Clinical}

From a clinical vantage point, many of the methodological issues raised here are common in all facets of psychiatric research. These include, the use of a small sample size, poorly defined, heterogeneous patient population, variability in illness duration and episode state, use of multiple medications and variable dosing, poor medication compliance, lack of age- and sex-matched healthy controls, and a lack of consideration for possible confounding variables including phase of menstrual cycle and history of substance abuse. While not exhaustive, consideration of the above would, according to this author, substantially strengthen any future studies into the neurochemistry of bipolar disorder.

\section{FUTURE DIRECTIONS}

While over 20 years have passed since Berridge and colleagues (35) supposition that bipolar disorder may be the result of PI-cycle hyperactivity, it was not until relatively recently that developments in technology enabled in vivo investigation of this novel hypothesis. Current evidence appears to lend support to PI-cycle involvement in bipolar disorder; however, it is still unclear whether this involvement is through inositoldepletion and whether it is primary or secondary. More data is indeed needed to clarify these issues. More specifically, future investigators would do well to consider the limitations outlined above during their planning stages. At the very least, particular attention needs to be focused on attaining a homogeneous population of bipolar patients, in sufficient numbers to allow for meaningful interpretation. Also, studies investigating the temporal relationship between medication effect on PI-cycle functioning and symptom improvement are warranted. Moreover, while most of the treatment studies discussed above evaluated lithium, data is urgently needed for the other commonly prescribed mood-stabilizing agents, among them; valproate, carbamazepine, lamotrigine and olanzapine. At this stage, it is uncertain whether these agents have similar effects on PI-cycle activity, although current evidence for valproate appears to suggest it does. In tandem with clinical MRS investigation of bipolar disorder, preclinical study of the effects of the moodstabilizing agents outlined above is in much demand. The power of high field preclinical magnets - on the order of $11.7 \mathrm{~T}$ and up to $18.8 \mathrm{~T}$ - and the capability of controlled pharmacological manipulation will fill the dearth of information and could provide independent verification of clinical findings.

\section{REFERENCES}

1. Kraepelin E. Lectures on Clinical Psychiatry, Third English Edition. London: Bailliere, Tindall and Cox, 1913.

2. Kraepelin E. One Hundred Years of Psychiatry. New York, NY: Philosophical Library, 1962.

3. Marneros A, Angst J. (eds.). Bipolar Disorders: 100 Years after Manic Depressive Insanity. Dordrecht: Kluwer, 2000.

4. Adams F. (ed.). The Extant Works of Aretaeus, the Cappadocian. London: Sydenham Society, 1856.

5. McElroy SL, Keck PE Jr., Strakowski SM. Mania, Psychosis and Antipsychotics. Journal of Clinical Psychiatry 57:14-26; 1996.

6. Marneros A, Brieger P. Prognosis of Bipolar Disorder: A Review. In: Maj M, Akiskal HS, Lopez-Ibor JJ, Sartorius N, eds. WPA Series, Evidence and Experience in Psychiary, Volume 5: Bipolar Disorder. United Kingdom: John Wiley \& Sons, 2002:97-148.

7. Tomb DA. Psychiatry, Sixth Edition. Philadelphia: Lippincott Williams \& Wilkins, 1999.

8. Goodwin FK, Jamison KR. Manic-Depressive Illness. New York, NY: Oxford University Press, 1990.

9. Regier DA, Boyd JH, Burke JD Jr. et al. One-Month Prevalence of Mental Disorders in the United States. Based on Five Epidemiologic Catchment Area Sites. Archives of General Psychiatry 45:977-986; 1988.

10. Angst J. The Emerging Epidemiology of Hypomania and Bipolar II Disorder. Journal of Affective Disorders 50:143-151; 1998.

11. Akiskal HS, Pinto O. The Evolving Bipolar Spectrum. Prototypes I, II, III, and IV. Psychiatric Clinics of North America 22:517-534; 1999.

12. Murray CJL, Lopez AD. (eds.). The Global Burden of Disease: A Comprehensive Assessment of Mortality and Disability from Diseases, Injuries and Risk Factors in 1990 and Projected to 2020. (Harvard University Press, Cambridge, 1996) (Global Burden of disease and Injury Series, Vol. 1).

13. Ustun TB, Chisholm D. Global Burden of Disease - Study for Psychiatric Disorders. Psychiatrische Praxis 28:7-11; 2001.

14. Akiskal HS. Classification, Diagnosis and Boundaries of Bipolar Disorders: A Review. In: Maj M, Akiskal HS, LopezIbor JJ, Sartorius N, eds. WPA Series, Evidence and Experience in Psychiary, Volume 5: Bipolar Disorder. United Kingdom: John Wiley \& Sons, 2002:1-52. 
15. Sachs GS. Treatment-Resistant Bipolar Depression. Psychiatric Clinics in North America 19:215-236; 1996.

16. Kasper S. Bipolar Disorder: A New Field for Rational Polypharmacy. In: Maj M, Akiskal HS, Lopez-Ibor JJ, Sartorius N, eds. WPA Series, Evidence and Experience in Psychiary, Volume 5: Bipolar Disorder. United Kingdom: John Wiley \& Sons, 2002:275-276.

17. Keck PE Jr., McElroy SL, Richtand N, Tohen M. What Makes a Drug a Primary Mood Stabilizer? Molecular Psychiatry 7:S8S14; 2002.

18. Fieve RR. Lithium Therapy at the Millennium: A Revolutionary Drug used for 50 Years faces Competing Options and Possible Demise. Bipolar Disorder 1:67-70;1999.

19. Cade J. Lithium Salts in the Treatment of Psychotic Excitement. Medical Journal of Australia 36:349-352; 1949.

20. Post RM, Weiss SRB, Clark M, et al. Lithium, Carbamazepine, and Valproate in Affective Illness. In: Manji $\mathrm{H}$, Bowden CL, Belmaker RH, eds. Bipolar Medications: Mechanisms of Action. Washington, DC: American Psychiatric Press Inc., 2000:219-248.

21. Davis JM, Janicak PG, Hogan DM. Mood Stabilizers in the Prevention of Recurrent Affective Disorders: A Meta-Analysis. Acta Psychiatrica Scandinavia 100:406-417; 1999.

22. Kusumaker V, Yatham LN, Haslam, DR, et al. Treatment of Mania, Mixed States, and Rapid Cycling. Canadian Journal of Psychiatry 42:79S-86S; 1997.

23. Calabrese JR. Efficacy of Lamotrigine in Bipolar Disorder. In: Manji H, Bowden CL, Belmaker RH, eds. Bipolar Medications: Mechanisms of Action. Washington, DC: American Psychiatric Press Inc., 2000:367-374.

24. Calabrese JR, Bowden CL, Sachs G, et al. A Placebo-controlled 18-Month Trail of Lamotrigine and Lithium Maintenance Treatment in Recently Depressed Patients with Bipolar I Disorder. Journal of Clinical Psychiatry 64:1013-1024; 2003.

25. Calabrese JR, Bowden CL, Sachs G, et al. A Double-Blind Placebo-Controlled Study of Lamotrigine Monotherapy in Outpatients with Bipolar I Depression. Journal of Clinical Psychiatry 60:79-88; 1999.

26. Baldassano CF, Datto SM, Littman L, Lipari MA. What Drugs Are Best for Bipolar Depression? Annals of Clinical Psychiatry 15:225-232; 2003.

27. Goldsmith DR, Wagstaff AJ, Ibbotson T, Perry CM. Spotlight on Lamotrigine in Bipolar Disorder. CNS Drugs 18:63-67; 2004.

28. Tohen M, Tollefson GD. Atypical Antipsychotic Agents in Mania: Clinical Studies. In: Manji H, Bowden CL, Belmaker RH, eds. Bipolar Medications: Mechanisms of Action. Washington, DC: American Psychiatric Press Inc., 2000:375388.

29. Moore GJ, Galloway MP. Magnetic Resonance Spectroscopy: Neurochemistry and Treatment Effects in Affective Disorders. Psychopharmacology Bulletin 36:5-23; 2002.

30. Greenshaw AJ. Neurotransmitter Interactions in Psychotropic Drug Action: Beyond Dopamine and Serotonin. Journal of Psychiatry \& Neuroscience 28:247-250; 2003.

31. Allison JH, Stewart MA. Reduced Brain Inositol in LithiumTreated Rats. Nature New Biology 233:267-268; 1971.

32. Allison JH, Blisner ME, Holland WH, Hipps PP, Sherman WR. Increased Brain Myo-Inositol 1-Phosphate in Lithium-Treated Rats. Biochemical and Biophysical Research Communications 71:664-670; 1976.

33. Wasserman MJ, Corson TW, Sibony D, Cooke RG, Parikh SV, Pennefather PS, Li PP, Warsh JJ. Chronic Lithium Treatment Attenuates Intracellular Calcium Mobilization. Neuropsychopharmacology 29:759-769; 2004.

34. Fisher SK, Heacock AM, Agranoff BW. Inositol Lipids and
Signal Transduction in the Nervous System: An Update. Journal of Neurochemistry 58:18-38; 1992.

35. Berridge MJ, Downes CP, Hanley MR. Lithium Amplifies Agonist- Dependent Phosphatidylinositol Responses in Brain and Salivary Glands. Biochemistry Journal 206:587-595; 1982.

36. Berridge MJ, Downes CP, Hanley MR. Neural and Developmental Actions of Lithium: A Unifying Hypothesis. Cell 59:411-419; 1989.

37. Gani D, Downes CP, Batty I, Bramham J. Lithium and MyoInositol Homeostasis. Biochimica et Biophysica Acta 1177:253-269; 1993.

38. del Rio E, Shinomura T, van der Kaay J, Nicholls DG, Downes CP. Disruption by Lithium of Phosphoinositide Signalling in Cerebellar Granule Cells in Primary Culture. Journal of Neurochemistry 70:1662-1669; 1998.

39. Jenkinson S, Patel N, Nahorski SR, Challiss RAJ. Comparative Effects of Lithium on the Phosphoinositide Cycle in Rat Cerebral Cortex, Hippocampus, and Striatum. Journal of Neurochemistry 61:1082-1090; 1993.

40. Sun GY, Navidi M, Yoa FG, Lin TN, Orth OE, Stubbs EB, Jr., MacQuarrie RA. Lithium Effects on Inositol Phospholipids and Inositol Phosphates: Evaluation of an In Vivo Model for Assessing Polyphosphoinositides Turnover in Brain. Journal of Neurochemistry 58:290-297; 1992.

41. Williams RSB, Cheng L, Mudge AW, Harwood AJ. A Common Mechanism of Action for Three Mood-Stabilizing Drugs. Nature 417:292-295; 2002.

42. Atack JR. Lithium, Phosphatidylinositol Signaling, and Bipolar Disorder: The Role of Inositol Monophosphatase. In: Manji HK, Bowden CL, Belmaker RH, eds. Bipolar Medications: Mechanisms of Action. Washington, DC: American Psychiatric Press Inc., 2000:1-30.

43. Desmond P, Tress B. Magnetic Resonance Imaging. In: Ames D, Chiu E, eds. Neuroimaging and the Psychiatry of Late Life. United Kingdom: Cambridge University Press, 1997:23-42.

44. Brandao LA, Dominques RC. MR Spectroscopy of the Brain. New York, NY: Lippincott Williams \& Wilkins, 2004.

45. Silverstone PH, Wu RH, O'Donnell T, Ulrich M, Asghar SJ, Hanstock CC. Chronic Treatment with both Lithium and Sodium Valproate may normalize Phosphoinositol Cycle Activity in Bipolar Patients. Human Psychopharmacology: Clinical and Experimental 17:321-327; 2002.

46. Salibi N, Brown MA. Clinical MR Spectroscopy: First Principles. New York, NY: Wiley-Liss, 1998.

47. Agam G, Shimon H. Human Evidence of the Role of Inositol in Bipolar Disorder and Antibipolar Treatment. In: Manji HK, Bowden CL, Belmaker RH, eds. Bipolar Medications: Mechanisms of Action. Washington, DC: American Psychiatric Press Inc., 2000:31-45.

48. O'Donnell T, Rotzinger S, Nakashima TT, Hanstock CC, Ulrich M, Silverstone PH. Chronic Lithium and Sodium Valproate both Decrease the Concentration of Myo-Inositol and Increase the Concentration of Inositol Monophosphates in Rat Brain. Brain Research 880:84-91; 2000.

49. Frey R, Metzler D, Fischer P, Heiden A, Scharfetter J, Moser E, Kasper S. Myo-Inositol in Depressive and Healthy Subjects determined by Frontal 1H-Magnetic Resonance Spectroscopy at 1.5 Tesla. Journal of Psychiatric Research 32:411-420; 1998.

50. Moore GJ, Bebchuk JM, Parrish JK, et al. Temporal Dissociation between Lithium-Induced Changes in Frontal Lobe Myo-Inositol and Clinical Response in Manic-Depressive Illness. American Journal of Psychiatry 156:1902-1908; 1999.

51. Moore CM, Breeze JL, Gruber SA, Babb SM, Frederick BB, Villafuerte RA, Stoll AL, Hennen J, Yurgelun-Todd DA, Cohen BM, Renshaw PF. Choline, Myo-Inositol and Mood in Bipolar 
Disorder: A Proton Magnetic Resonance Spectroscopic Imaging Study of the Anterior Cingulate Cortex. Bipolar Disorders 2:207-216; 2000.

52. Kato T, Takahashi S, Shioiri T, Inubushi T. Brain Phosphorous Metabolism in Depressive Disorders Detected by Phosphorus31 Magnetic Resonance Spectroscopy. Journal of Affective Disorders 26:223-230; 1992.

53. Kato T, Shioiri T, Murashita J, Hamakawa H, Inubushi $\mathrm{T}$, Takahashi S. Phosphorus-31 Magnetic Resonance Spectroscopy and Ventricular Enlargement in Bipolar Disorder. Psychiatric Research 55:41-50; 1994b.

54. Kato T, Shioiri T, Murashita J, et al. Lateralized Abnormality of the High Energy Phosphate Metabolism in the Frontal Lobes of Patients with Bipolar Disorder Detected by Phase-Encoded 31P MRS. Psychological Medicine 25:557-566; 1995.

55. Volz HP, Rzanny R, Riehemann S, May S, Hegewald H, Preussler B, Hubner G, Kaiser WA, Sauer H. 31P Magnetic Resonance Spectroscopy in the Frontal Lobe of Major Depressed Patients. European Archives of Psychiatry and Clinical Neuroscience 248:289-295; 1998.

56. Moore CM, Christensen JD, Lafer B, Fava M, Renshaw PF. Lower Levels of Nucleoside Triphosphate in the Basal Ganglia of Depressed Subjects: A Phosphorous-31 Magnetic Resonance Spectroscopy Study. American Journal of Psychiatry 154:116$118 ; 1997$.

57. Auer DP, Putz B, Kraft E, Lipinski B, Schill J, Holsboer F. Reduced Glutamate in the Anterior Cingulate Cortex in Depression: An In Vivo Proton Magnetic Resonance Spectroscopy Study. Biological Psychiatry 47:305-313; 2000.

58. Gruber S, Frey R, Mlynarik V, Stadlbauer A, Heiden A, Kasper S, Kemp GJ, Moser E. Quantification of Metabolic Differences in the Frontal Brain of Depressive Patients and Controls Obtained by $1 \mathrm{H}-\mathrm{MRS}$ at 3 Tesla. Investigational Radiology 38:403-408; 2003.

59. Davanzo P, Thomas MA, Yue K, et al. Decreased Anterior Cingulate Myo-inositol/Creatine Spectroscopy Resonance with Lithium Treatment in Children with Bipolar Disorder. Neuropsychopharmacology 24:359-369; 2001.

60. Davanzo P, Yue K, Thomas MA, Belin T, Mintz J, Venkatraman TN, Santoro E, Barnett S, McCracken J. Proton Magnetic Resonance Spectroscopy of Bipolar Disorder versus Intermittent Explosive Disorder in Children and Adolescents. American Journal of Psychiatry 160:1442-1452; 2003.

61. Sharma R, Venkatasubramanian PN, Barany M, Davis JM. Proton Magnetic Resonance Spectroscopy of the Brain in Schizophrenic and Affective Patients. Schizophrenia Research 8:43-49; 1992.

62. Kato T, Shioiri T, Takahashi S, Inubushi T. Measurement of Brain Phosphoinositide Metabolism in Bipolar Patients using in vivo 31P-MRS. Journal of Affective Disorders 22:185-190; 1991.

63. Kato T, Takahashi S, Shioiri T, Inubushi T. Alterations in Brain Phosphorus Metabolism in Bipolar Disorder defected by in vivo 31P and 7Li Magnetic Resonance Spectroscopy. Journal of Affective Disorders 27:53-59; 1993.

64. Cecil KM, DelBello MP, Morey R, Strakowski SM. Frontal Lobe Differences in Bipolar Disorder as Determined by Proton MR Spectroscopy. Bipolar Disorders 4:357-365; 2002.

65. Winsberg ME, Sachs N, Tate DL, Adalsteinsson E, Spielman
DM, Ketter TA. Decreased Dorsolateral Prefrontal N-Acetyl Aspartate in Bipolar Disorder. Biological Psychiatry 47:475$481 ; 2000$.

66. Deicken RF, Fein G, Weiner MW. Abnormal Frontal Lobe Phosphorous Metabolism in Bipolar Disorder. American Journal of Psychiatry 152:915-918; 1995a.

67. Deicken RF, Weiner MW, Fein G. Decreased Temporal Lobe Phosphomonoesters in Bipolar Disorder. Journal of Affective Disorders 33:195-199; 1995 b.

68. Kato T, Murashita J, Kamiya A, Shioiri T, Kato N, Inubushi T. Decreased Brain Interacellular pH Measured by 31P-MRS in Bipolar Disorder: A Confirmation in Drug-Free Patients and Correlation with White Matter Hyperintensity. European Archives of Psychiatry and Clinical Neuroscience 248:301-306; 1998.

69. Bruhn H, Stoppe G, Staedt J, Merboldt KD, Hanicke W, Frahm J. Quantitative Proton MRS in vivo shows Cerebral MyoInositol and Cholines to be Unchanged in Manic-Depressive Patients Treated with Lithium. In Society of Magnetic Resonance in Medicine: August 14-20 1993; New York. 1543.

70. Kato T, Takahashi S, Shioiri T, Murashita J, Hamakawa H, Inubushi T. Reduction of Brain Phosphocreatine in Bipolar II Disorder Detected by Phosphorus-31 Magnetic Resonance Spectroscopy. Journal of Affective Disorders 31:125-133; 1994a.

71. Murashita J, Kato T, Shioiri T, Inubushi T, Kato N. Altered Brain Energy Metabolism in Lithium-Resistant Bipolar Disorder Detected by Photic Stimulated 31P-MR Spectroscopy. Psychological Medicine 30:107-115; 2000.

72. Hamakawa H, Murashita J, Yamada N, Inubushi T, Kato N, Kato T. Reduced Intracellular pH in the Basal Ganglia and Whole Brain Measured by 31P-MRS in Bipolar Disorder. Psychiatry and Clinical Neuroscience 58:82-88; 2004.

73. Chang K, Adleman N, Dienes K, Barnea-Goraly N, Reiss A, Ketter T. Decreased N-Acetylaspartate in Children with Familial Bipolar Disorder. Biological Psychiatry 53:1059-1065; 2003.

74. Silverstone PH, Hanstock CC, Fabian J, Staab R, Allen PS. Chronic Lithium does not alter Human Myo-Inositol or Phosphomonoester Concentrations as Measured by $1 \mathrm{H}$ and 31P MRS. Biological Psychiatry 40:235-246; 1996.

75. Silverstone PH, Rotzinger S, Pukhovsky A, Hanstock CC. Effects of Lithium and Amphetamine on Inositol Metabolism in the Human Brain as Measured by $1 \mathrm{H}$ and 31P MRS. Biological Psychiatry 46:1634-1641; 1999.

76. Yildiz A, Demopulos CM, Moore CM, Renshaw PF, Sachs GS. Effect of Lithium on Phosphoinositide Metabolism in Human Brain: A Proton Decoupled 31P Magnetic Resonance Spectroscopy Study. Biological Psychiatry 50:3-7; 2001.

77. Jacobs D, Silverstone T. Dextroamphetamine-Induced Arousal in Human Subjects as a Model for Mania. Psychological Medicine 16:323-329; 1986.

78. Hamakawa H, Kato $\mathrm{T}$, Shioiri $\mathrm{T}$, Inubushi $\mathrm{T}$, Kato, $\mathrm{N}$. Quantitative Proton Magnetic Resonance Spectroscopy of the Bilateral Frontal Lobes in Patients with bipolar disorder. Psychological Medicine 29:639-644; 1999.

79. Deicken RF, Eliaz Y, Feiwell R, Schuff N. Increased Thalamic N- Acetylaspartate in Male Patients with Familial Bipolar I Disorder. Psychiatry Research: Neuroimaging Section 106(1):35-45; 2001.

Brent M. McGrath is a Doctoral student in the Department of Psychiatry at the University of Alberta (Edmonton, AB, Canada). He holds a B.Sc. in Biology and Psychology from the University of New Brunswick (Saint John, NB, Canada), and a M.Sc. in Psychiatry from McGill University (Montréal, QC, Canada). His research interests are diverse, including magnetic resonance spectroscopic investigations into the neuropathophysiology of bipolar disorder, as well as ex vivo neurochemical study of psychopharmacological agents. He also investigates important issues in social psychiatry, including quality of life, stigma and patient satisfaction. 